\title{
LETTER
}

\section{Fabrication of disk-shaped, deuterated resorcinol/formaldehyde foam target for laser-plasma experiments}

\author{
Yumi Kaneyasu ${ }^{1}$, Keiji Nagai ${ }^{1,2}$, Marilou Cadatal-Raduban ${ }^{1,3}$, Daniil Golovin ${ }^{1}$, Satoshi Shokita ${ }^{1}$, \\ Akifumi Yogo ${ }^{1}$, Takahisa Jitsuno ${ }^{1}$, Takayoshi Norimatsu ${ }^{1}$, and Kohei Yamanoi ${ }^{1}$ \\ ${ }^{1}$ Institute of Laser Engineering, Osaka University, Osaka, Japan \\ ${ }^{2}$ Institute of Innovative Research (IIR), Tokyo Institute of Technology - Suzukakedai Campus, Yokohama, Japan \\ ${ }^{3}$ Centre for Theoretical Chemistry and Physics, School of Natural and Computational Sciences, Massey University, Auckland, \\ New Zealand \\ (Received 30 November 2020; revised 22 February 2021; accepted 17 March 2021)
}

\begin{abstract}
Resorcinol/formaldehyde (RF) foam resin is an attractive material as a low-density target in high-power laser-plasma experiments because of its fine network structure, transparency in the visible region, and low- $Z$ element (hydrogen, carbon, and oxygen) composition. In this study, we developed disk-shaped RF foam and deuterated RF foam targets with 40-200 $\mu \mathrm{m}$ thickness and approximately $100 \mathrm{mg} / \mathrm{cm}^{3}$ density having a network structure from $100 \mathrm{~nm}$ to a few micrometers cell size. By deuteration, the polymerization rate was drastically slowed down owing to kinetic isotope effects. These targets were used in high-power laser experiments where a megaelectronvolt proton beam was successfully generated.
\end{abstract}

Keywords: deuterated material; low-density material; resorcinol/formaldehyde foam

\section{Introduction}

In high-power laser-plasma experiments, low-density porous materials with high specific surface areas are more advantageous in producing a controlled low-density plasma compared with their bulk counterparts because the nearcritical density region in the wavelength range of the highpower laser is between the density of solid and liquid phases. Some of the methods used to reach critical density include using cluster targets ${ }^{[1]}$ and pre-laser irradiation on solid film ${ }^{[2]}$. However, it is difficult to control the density using these methods. Moreover, a dedicated target equipment and an additional laser are needed. In a recent laser-plasma interaction study, Yogo et al. reported that the picosecond relativistic-intensity $\left(>10^{18} \mathrm{~W} \mathrm{~cm}^{-2}\right)$ laser pulses focused on a solid film target can generate nonlinear electron acceleration and high-efficiency ion acceleration ${ }^{[3,4]}$. Their

Correspondence to: K. Yamanoi, Institute of Laser Engineering, Osaka University, 2-6 Yamadaoka, Suita, Osaka 565-0871, Japan. Email: yamanoi-k@ile.osaka-u.ac.jp results indicate that picosecond relativistic-intensity laser pulses focused onto the near-critical density targets lead to a higher plasma heating efficiency. For example, efficient ion acceleration and magnetic reconnection are demonstrated using picosecond laser and low-density targets ${ }^{[5,6]}$. Resorcinol/formaldehyde (RF) aerogel is a notable laser plasma target material owing to its fine network structure, low density of $10-200 \mathrm{mg} / \mathrm{cm}^{3}$, transparency in the visible region, and low- $Z$ element (hydrogen, carbon, and oxygen) composition $^{[7,8]}$. Shell-shaped RF targets have been developed for inertial fusion experiments ${ }^{[9-17]}$ and its cryogenic targets ${ }^{[18,19]}$. Low-density materials have low mechanical strengths. Therefore, a holder is needed to support these materials during the shaping process ${ }^{[14,20,21]}$. Fabrication of deuterated targets is also important for inertial fusion experiments. However, controlling their shape and density has proven to be difficult owing to their high reactivity at room temperature ${ }^{[22-24]}$. Recently, low-density targets, in the form of thin films and flat-surface targets, are being required for laser acceleration experiments whereas deuterated targets are useful for distinguishing the origin of the generated proton 
or deuteron ions. The chemistry of RF foam fabrication has two kinds of electrophile substitution reactions to resorcinol, which is a very reactive aromatic compound, as shown in Figure $1^{[25,26]}$. The first reaction is the attack of formaldehyde, forming a methylol group $\left(-\mathrm{CH}_{2} \mathrm{OH}\right)$ at the aromatic ring. The second reaction is the attack of the methylol group to another aromatic ring, forming a polymer and crosslinking. Based on this chemistry, the fabrication process has two steps and each step is slightly different. In the first step, a linear polymer is formed and a viscous polymer solution is obtained from the two chemical reactions described previously. The second step is gelation based on crosslinking. In general, molding should be done after the first step for the viscous solution around $30 \mathrm{mPa}$ s. Furthermore, the solution exchange and extraction process may induce expansion or shrinkage of the gel. Therefore, the target fabrication should consider such volume changes. The purpose of this study is to fabricate disk-shaped RF foam targets for laser-particle acceleration experiments. To make disk-shaped and polymerized targets at room temperature, a paper holder was filled with deuterated resorcinol, formaldehyde, and heavy water $\left(\mathrm{D}_{2} \mathrm{O}\right)$. After polymerization, the $\mathrm{D}_{2} \mathrm{O}$ was replaced with acetone, and the target was dried using the supercritical drying method. The fabricated target has a thickness of $100 \mu \mathrm{m}$ and a density of $30 \mathrm{mg} / \mathrm{cm}^{3}$. We found that the polymerization rate and the viscosity during the polymerization process were different compared with a normal RF (n-RF) foam.

\section{Fabrication of RF foams}

A normal RF (n-RF) foam was made from the normal resorcinol $\left(\mathrm{C}_{6} \mathrm{H}_{6} \mathrm{O}_{2} ; \mathrm{n}-\mathrm{R}\right)$ and normal $37 \%$ (mass fraction)

(a) Proton (or deuteron) elimination
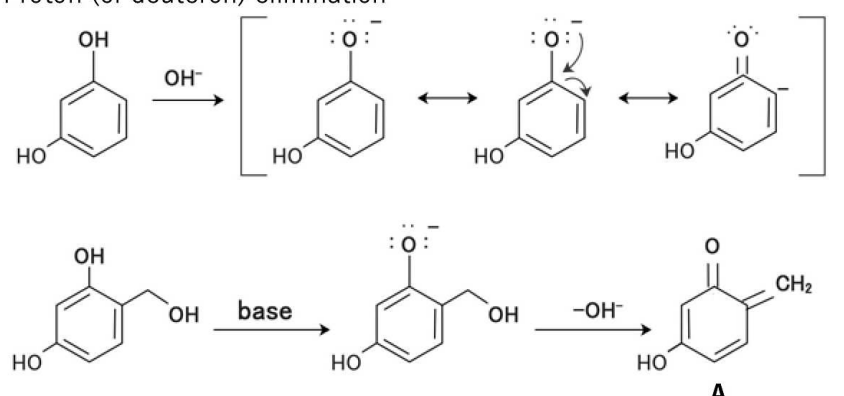

A

Attack of formaldehyde<smiles>[B]c1ccc(O)c(C=O)c1</smiles>

Condensation to $\mathrm{CH}_{2}\left(\mathrm{CD}_{2}\right)$ bridge

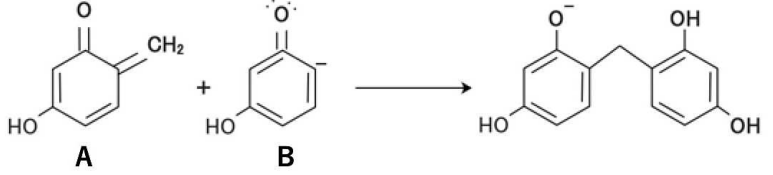

(b)
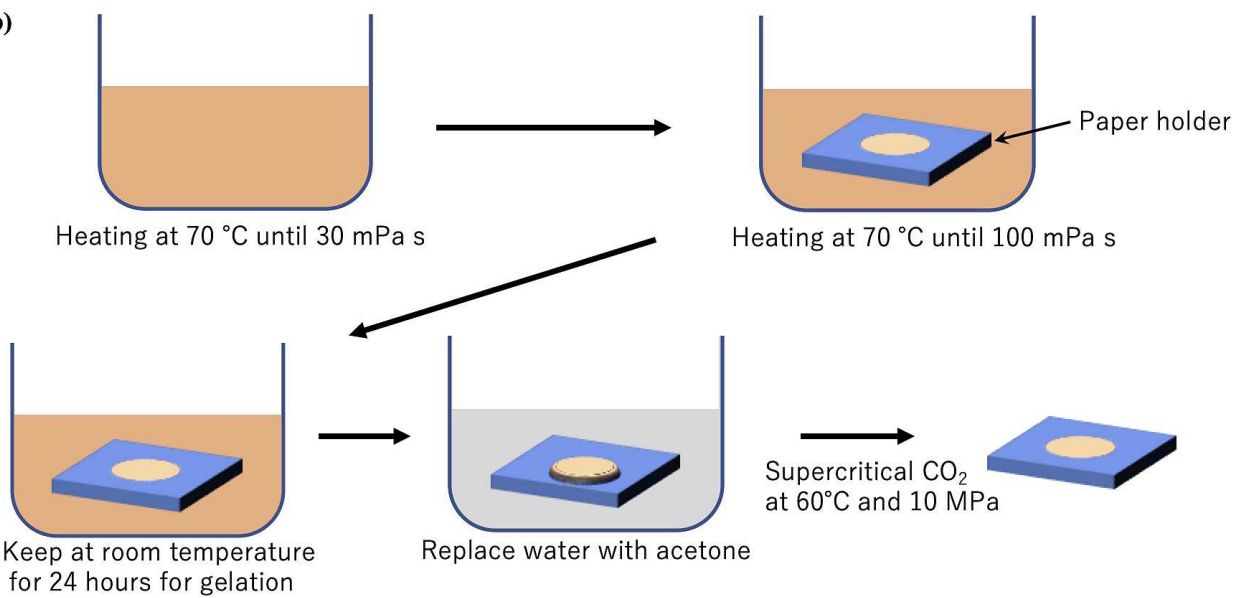

Heating at $70^{\circ} \mathrm{C}$ until $100 \mathrm{mPa} \mathrm{s}$

Supercritical $\mathrm{CO}_{2}$ at $60^{\circ} \mathrm{C}$ and $10 \mathrm{MPa}$

Figure 1. Schematic diagram of (a) the chemical reaction and (b) procedures. 
Table 1. Information about samples and each time to reach $100 \mathrm{mPa}$ s by polymerization.

\begin{tabular}{lccccc}
\hline & Resorcinol & Formaldehyde & Water & R/C & $\begin{array}{c}\text { Time to reach } \\
100 \mathrm{mPa} \text { s (min) }\end{array}$ \\
\hline n-RF 50 & Normal & Normal & Normal & 50 & 120 \\
n-RF100 & Normal & Normal & Normal & 100 & 270 \\
n-RF200 & Normal & Normal & Normal & 200 & 320 \\
d-R/n-F50 & Deuterated & Normal & Deuterated & 50 & 140 \\
n-R/d-F50 & Normal & Deuterated & Deuterated & 50 & 240 \\
d-RF50 $+\mathrm{H}_{2} \mathrm{O}$ & Deuterated & Deuterated & Normal & 50 & 240 \\
d-RF50 $+\mathrm{D}_{2} \mathrm{O}$ & Deuterated & Deuterated & Deuterated & 50 & 280 \\
\hline
\end{tabular}

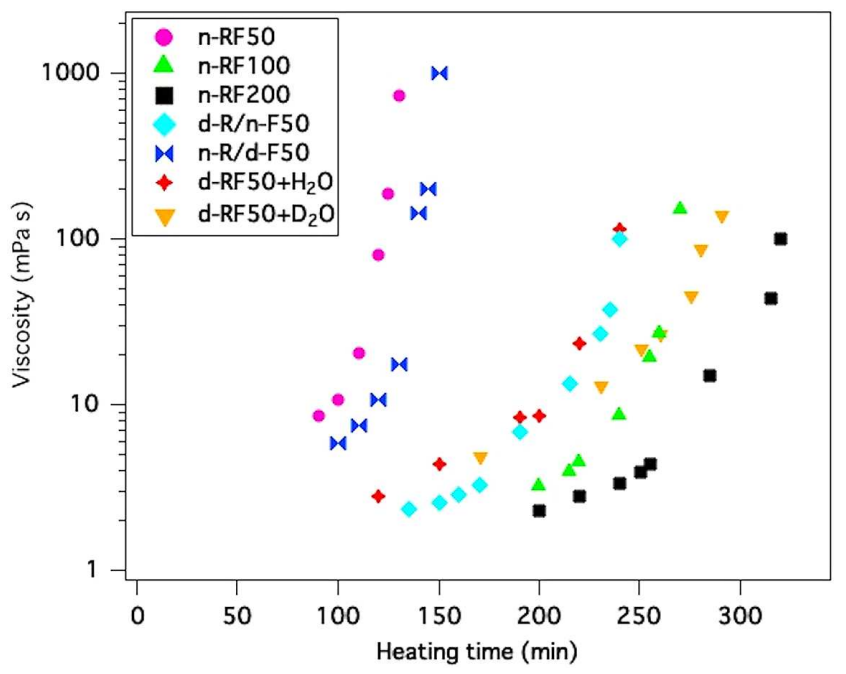

Figure 2. Change in viscosity during polymerization for each sample.

formalin $\left(\mathrm{CH}_{2} \mathrm{O} ; \mathrm{n}-\mathrm{F}\right)$ at a ratio of $\mathrm{n}-\mathrm{R}: \mathrm{n}-\mathrm{F}=1: 2$. A $2.8 \%$ (mass fraction) $\mathrm{Na}_{2} \mathrm{CO}_{3}$ aqueous solution was added as a catalyst $(\mathrm{C})$ or polymerization initiator at a ratio of $n$ $\mathrm{R}: \mathrm{C}=200: 1$. Figure 1 shows the schematic diagram of the process. The starting materials were stirred at $70^{\circ} \mathrm{C}$ in a vial for polymerization until the viscosity became $30 \mathrm{mPa}$. The heating was stopped and a paper holder on a glass slide was filled with the n-RF polymer solution to mold the RF polymer. The paper holder had a $0.5 \mathrm{~mm}$ diameter hole. The $\mathrm{n}$-RF polymer solution was heated at $70^{\circ} \mathrm{C}$ again until the viscosity of the outer side solution of the holder became $100 \mathrm{mPa}$ s. After heating, the solution was kept at room temperature for $24 \mathrm{~h}$ to form a mechanically stable crosslinked gel. Then, the pure $\mathrm{H}_{2} \mathrm{O}$ in the n-RF gel was replaced with acetone. Next, the $\mathrm{n}-\mathrm{RF}$ gel with a paper holder in acetone was dried using the supercritical $\mathrm{CO}_{2}$ drying method at $60^{\circ} \mathrm{C}$ and $10 \mathrm{MPa}$. We also tried using a more stable holder such as metal. To mold low-density materials during the shaping process, a metallic mold is used to make disks, cylinders, and washers ${ }^{[14,20,21]}$. However, although the metal holder was stable and flat, it could not hold an n-RF foam because the RF foam expanded and then shrunk during acetone replacement. To the best of our understanding, a paper holder (ADVANTEC filter paper) is the most stable material for holding the n-RF foam because the network structure of the $\mathrm{n}$-RF foam becomes entangled with the paper holder.

The deuterated RF (d-RF) foam was made using the same process as that of the n-RF foam described previously, but using the deuterated resorcinol $\left(\mathrm{C}_{6} \mathrm{D}_{6} \mathrm{O}_{2} ; \mathrm{d}-\mathrm{R}\right)$, deuterated $20 \%$ (mass fraction) formalin $\left(\mathrm{CD}_{2} \mathrm{O} ; \mathrm{d}-\mathrm{F}\right), \mathrm{D}_{2} \mathrm{O}$, and $\mathrm{Na}_{2} \mathrm{CO}_{3}$ from CDN Isotopes. The ratios of d-R:d-F and dR:C were 1:2 and 50:1, respectively. After the second heating process, the gel was kept at room temperature for 7 days to form a stable crosslinked gel. The same molding process that was used for the n-RF foam was also used to shape the d-RF foam.

For comparison, we also made the following pairs: $n-R$ and d-F with $\mathrm{D}_{2} \mathrm{O}$, d-R and $\mathrm{n}-\mathrm{F}$ with $\mathrm{D}_{2} \mathrm{O}$, and d-R and d-F with $\mathrm{H}_{2} \mathrm{O}$ as starting materials. Using these deuterated materials, we were unable to make a polymer with more than $\mathrm{R} / \mathrm{C}=50$. However, the $\mathrm{n}-\mathrm{RF}$ could be polymerized with $\mathrm{R} / \mathrm{C}=200$. Information about the samples is listed in Table 1. For all samples, the viscosity was monitored by a viscometer (Brookfield DV-II+Pro) during fabrication. All samples were characterized using scanning electron microscopy (SEM) after fabrication.

\section{Results and discussion}

An RF solution with moderate viscosity needs to be obtained first. Then, the kinetics of polymerization is important from resorcinol and formaldehyde. Figure 2 compares the change in viscosity during polymerization for the following samples: $\mathrm{n}-\mathrm{RF}$ at $\mathrm{R} / \mathrm{C}=200,100$, and $50 ; \mathrm{d}-\mathrm{RF}$ with $\mathrm{D}_{2} \mathrm{O}$ at $\mathrm{R} / \mathrm{C}=50$; $\mathrm{d}-\mathrm{RF}$ with $\mathrm{H}_{2} \mathrm{O}$ at $\mathrm{R} / \mathrm{C}=50 ; \mathrm{d}-\mathrm{R} / \mathrm{n}-\mathrm{F}$ at $\mathrm{R} / \mathrm{C}=50$; and $\mathrm{n}-\mathrm{R} / \mathrm{d}-\mathrm{F}$ at $\mathrm{R} / \mathrm{C}=50$. In general, the mean viscosity $[\eta]$ is correlated to the mean molecular weight $M$ via the MarkHouwunk empirical formula $[\eta]=K M a$, where $a$ and $K$ are constants that depend on the polymer and solvent combination. The mean molecular weight or mean viscosity increases significantly owing to the step-growth polymerization of the $\mathrm{RF}$ foam. The initial viscosity is similar to that for water and is therefore too low to measure using the same experimental equipment. We observed that a higher $\mathrm{R} / \mathrm{C}$ resulted in slower polymerization in the $\mathrm{n}-\mathrm{RF}$ foam. The amount of initiator used is also important. Using too much initiator leads to a decrease in the molecular weight and, consequently, the 

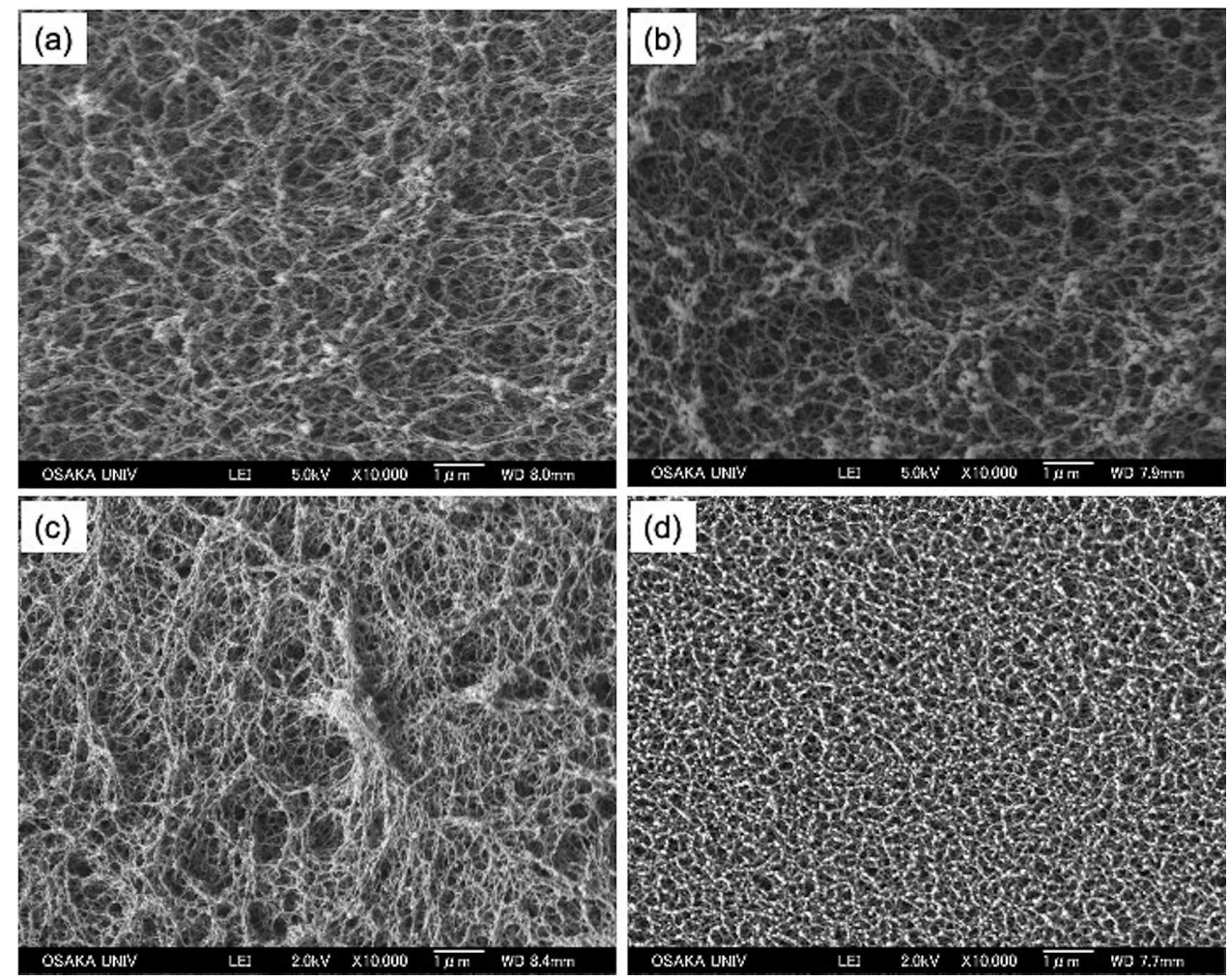

Figure 3. SEM images of (a) disk-shaped d-RF and (b) bulk d-RF fabricated at $R / C=50$ and 300 min heating time, (c) $n-R F$ fabricated at $R / C=200$ and 300 min heating time, and (d) $n-R F$ fabricated at $R / C=200$ and 350 min heating time.

mechanical toughness of the foam decreases, making it weak. On the other hand, the polymer is not formed if the amount of initiator is not enough. In our results, the d-RF was not polymerized when the $\mathrm{R} / \mathrm{C}$ ratio was higher than 50 .

The difference in polymerization rate is due to the kinetic isotope effect $(\mathrm{KIE})^{[27]}$. In general, the bonding related to the chemical reaction is deuterated and the effects are enhanced by primary KIE. From Table 1 and Figure 2, the polymerization rate decreased when the water was deuterated. This result suggests that the condensation reaction occurs between resorcinol and formaldehyde in the case of an RF material. The rate of viscosity increment or polymerization rate of d-RF with $\mathrm{D}_{2} \mathrm{O}$ was slowest, given the same $\mathrm{R} / \mathrm{C}$ ratio. Meanwhile, the polymerization rates were categorized into two groups. The slow rates for $\mathrm{n}-\mathrm{R} / \mathrm{d}-\mathrm{F}$ and $\mathrm{d}-\mathrm{R} / \mathrm{d}-\mathrm{F}+\mathrm{H}_{2} \mathrm{O}$ are almost the same as that of $\mathrm{d}-\mathrm{R} / \mathrm{d}-\mathrm{F}+\mathrm{D}_{2} \mathrm{O}$ (completely deuterated starting materials) given the same $\mathrm{R} / \mathrm{C}$ ratio. On the other hand, $d-R / n-F$ and $n-R / n-F$ had a similarly fast rate. It means that the KIE was observed only for formaldehyde, and not for resorcinol. These results are consistent with the electrophilic substitution of the aromatic ring initiated by the base catalyst because elimination of a hydrogen atom happens before the attack of the formaldehyde or aromatic methylene (Figure 1(a)), i.e., the resorcinol lost a hydrogen atom at the reactive carbon (Figure 1(b)). As for the KIE for electrophilic substitution of aromatic ring, acid catalysts were also exhibited only for the attack of the electrophile ${ }^{[28]}$, which is consistent with the present results in spite of the difference in the catalyst.

When we consider the second process, the RF solution should be moved to the next molding process before forming the network structure. Moreover, it is required that the viscosity should not exceed $100 \mathrm{mPa}$ s. Heating for a very long time increases the molecular weight, making the RF denser. Therefore, the slower reaction rate of $\mathrm{d}-\mathrm{RF}$ makes it easier to control the network structure and density. Aside from listing the information about each sample, Table 1 also lists the time it takes to reach $100 \mathrm{mPa}$ s for each sample. Previously, Yamagishi et al. reported the relationship between the molecular weight and the viscosity of polymerization reaction of phenol and formaldehyde ${ }^{[29]}$. From this relationship, the molecular weights at $100 \mathrm{mPa}$ s are estimated to be from 1000 to $10,000 \mathrm{~g} / \mathrm{mol}$.

The gelation process is also slow in the d-RF polymer solution. Figure 3 shows the SEM images of disk-shaped d-RF, bulk d-RF, and n-RF targets. The d-RF has a fibric network structure, with pore sizes ranging from $100 \mathrm{~nm}$ to a few micrometers. On the other hand, the structure of the n-RF depends on the gelation rate. For the case of slow gelation, a similar fibric network was observed as seen in Figure 3(c), whereas the rapid gelation had particle-like aggregations with a network structure (Figure 3(d)). For the molding process, the rapid gelation tends to exhibit some degree of shrinkage during gelation, 


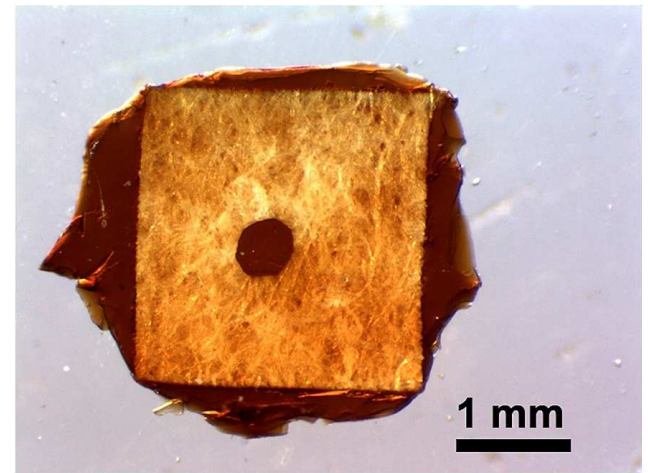

Figure 4. Photograph of the disk-shaped d-RF foam targets inside the holders.

which is not preferable for controlling the target shape. The particle-like aggregation is related to the shrinkage. For the d-RF polymer, gelation was also too slow so as not to form such particle-like structures. The SEM image of the bulk d-RF foam in Figure 3(b) shows that the network structure and pore size of the disk-shaped RF foam (Figure 3(a)) are similar with that of the bulk (Figure 3(b)). This indicates that there is no significant difference in the density of the bulk and disk-shaped RF foams.

Figure 4 shows a photograph of the disk-shaped d-RF foam targets inside the holders. The thickness of the target corresponds to the thickness of the paper holder, which was controlled such that it is thicker than $40 \mu \mathrm{m}$. A network structure with pore sizes ranging from $100 \mathrm{~nm}$ to a few micrometers was clearly observed in the SEM image. From the volume and the weight of the bulk d-RF foam, the density was estimated to be $30 \mathrm{mg} / \mathrm{cm}^{3}$. These foam targets were used in experiments for generating megaelectronvolt ion beams using a picosecond sub-kilojoule laser at Osaka University ${ }^{[5,6]}$. In these experiments, the foam target was used to enhance the conversion efficiency of ultra-intense laser energy into plasma leading to ion acceleration. The plasma density was controlled to be near the critical density by adjusting the laser pre-pulse intensity. As a result, the maximum energy of protons was enhanced up to $23 \mathrm{MeV}$ when the intensity of the laser was $6 \times 10^{18} \mathrm{~W} / \mathrm{cm}^{2}$. This enhancement is higher compared with the case when soliddensity targets are used.

\section{Conclusions}

In conclusion, a disk-shaped deuterated RF foam has been fabricated in this work. The thickness of the samples was controllable according to the thickness of the paper holder. The polymerization rate of the deuterated RF foam was drastically slowed down by KIEs compared with the normal $\mathrm{RF}$ foam. The fine network structures in d-RF are easier to control because the cell size of the network structure is related to the polymerization rate. These foam targets are expected to contribute to the advancement of laser-particle acceleration and high-energy-density physics.

\section{Acknowledgement}

This work was supported by the Collaboration Research Program between the National Institute for Fusion Science and the Institute of Laser Engineering at Osaka University (NIFS12KUGK057).

\section{References}

1. Y. Fukuda, A. Y. Faenov, M. Tampo, T. A. Pikuz, T. Nakamura, M. Kando, Y. Hayashi, A. Yogo, H. Sakaki, T. Kameshima, A. S. Pirozhkov, K. Ogura, M. Mori, T. Z. Esirkepov, J. Koga, A. S. Boldarev, V. A. Gasilov, A. I. Magunov, T. Yamauchi, R. Kodama, P. R. Bolton, Y. Kato, T. Tajima, H. Daido, and S. V. Bulanov, Phys. Rev. Lett. 103, 165002 (2009).

2. A. Yogo, H. Daido, S. V. Bulanov, K. Nemoto, Y. Oishi, T. Nayuki, T. Fujii, K. Ogura, S. Orimo, A. Sagisaka, J. L. Ma, T. Z. Esirkepov, M. Mori, M. Nishiuchi, A. S. Pirozhkov, S. Nakamura, A. Noda, H. Nagatomo, T. Kimura, and T. Tajima, Phys. Rev. E 77, 016401 (2008).

3. A. Yogo, K. Mima, N. Iwata, S. Tosaki, A. Morace, Y. Arikawa, S. Fujioka, T. Johzaki, Y. Sentoku, H. Nishimura, A. Sagisaka, K. Matsuo, N. Kamitsukasa, S. Kojima, H. Nagatomo, M. Nakai, H. Shiraga, M. Murakami, S. Tokita, J. Kawanaka, N. Miyanaga, K. Yamanoi, T. Norimatsu, H. Sakagami, S. V. Bulanov, K. Kondo, and H. Azechi, Sci. Rep. 7, 42451 (2017).

4. N. Iwata, K. Mima, Y. Sentoku, A. Yogo, H. Nagatomo, H. Nishimura, and H. Azechi, Phys. Plasmas 24, 073111 (2017).

5. S. Shokita, A. Yogo, S. R. Mirfayzi, Y. Honoki, D. Golovin, T. Ishimoto, Z. Lana, K. Matsuo, T. Mori, K. Okamoto, H. Nagatomo, H. Nishimura, Y. Sentoku, K. Yamanoi, and R. Kodama, High Ener. Den. Phy. 36, 100821 (2020).

6. D. O. Golovin, S. R. Mirfayzi, Y. J. Gu, Y. Abe, Y. Honoki, T. Mori, H. Nagatomo, K. Okamoto, S. Shokita, K. Yamanoi, Y. Arikawa, G. Korn, T. A. Pikuz, S. Fujioka, R. Kodama, S. V. Bulanov, and A. Yogo, High Ener. Den. Phy. 36, 100840 (2020).

7. R. W. Pekala, J. Mater. Sci. 24, 3221 (1989).

8. K. Nagai, C. S. A. Musgrave, and W. Nazarov, Phys. Plasmas 25, 030501 (2018).

9. S. M. Lambert, G. E. OverturfIII, G. Wilemski, S. A. Letts, D. Schroen-Carey, and R. C. Cook, J. Applied Polymer Sci. 65, 2111 (1997).

10. F. Ito, K. Nagai, M. Nakai, T. Norimatsu, A. Nikitenko, S. Tolokonnikov, E. Koresheva, T. Fujimura, H. Azechi, and K. Mima, Jpn. J. Appl. Phys Part 2 45, L335 (2006).

11. F. Ito, K. Nagai, M. Nakai, and T. Norimatsu, Fusion Sci. Technol. 49, 663 (2006).

12. K. Nagai, H. Yang, T. Norimatsu, H. Azechi, F. Belkada, Y. Fujimoto, T. Fujimura, K. Fujioka, S. Fujioka, H. Homma, F. Ito, A. Iwamoto, T. Jitsuno, Y. Kaneyasu, M. Nakai, N. Nemoto, H. Saika, T. Shimoyama, Y. Suzuki, K. Yamanaka, and K. Mima, Nucl. Fusion 49, 095028 (2009).

13. H. Yang, K. Nagai, M. Nakai, and T. Norimatsu, Laser Part. Beams 26, 449 (2008).

14. R. R. Paguio, J. F. Hund, B. E. Blue, D. G. Schroen, K. M. Saito, C. A. Frederick, R. J. Strauser, and K. Quan, Fusion Sci. Technol. 55, 450 (2009).

15. R. R. Paguio, D. Jaison, K. M. Saito, K. Quan, J. F. Hund, and A. Nikroo, Fusion Sci. Technol. 59, 199 (2011). 
16. R. R. Paguio, M. Takagi, M. Thi, J. F. Hund, A. Nikroo, S. Paguio, R. Luo, A. L. Greenwood, O. Acenas, and S. Chowdhury, Fusion Sci. Technol. 51, 682 (2007).

17. C. A. Frederick, R. R. Paguio, A. Nikroo, J. H. Hund, O. Acennas, and M. Thi, Fusion Sci. Technol. 49, 657 (2006).

18. A. Iwamoto, Plasma Fusion Res. 15, 2404006 (2020).

19. T. Fujimura, T. Norimatsu, M. Nakai, K. Nagai, A. Iwamoto, and K. Mima, Fusion Sci. Technol. 51, 677 (2007).

20. K. A. DeFriend, B. F. Espinoza, A. Nobile, K. V. Salazar, R. D. Day, N. E. Elliott, T. H. Pierce, J. E. Elliott, D. W. Schmidt, F. Fierro, D. Sandoval, J. F. Griego, A. C. Valdez, and M. Droege, Fusion Sci. Technol. 49, 701 (2006).

21. K. A. DeFriend, B. Espinoza, and B. Patterson, Fusion Sci. Technol. 51, 693 (2007).

22. K. Nagai, H. Azechi, F. Ito, A. Iwamoto, Y. Izawa, T. Johzaki, R. Kodama, K. Mima, T. Mito, M. Nakai, N. Nemoto, T.
Norimatsu, Y. Ono, K. Shigemori, H. Shiraga, and K. A. Tanaka, Nucl. Fusion 45, 1277 (2005).

23. F. Ito, K. Nagai, M. Nakai, and T. Norimatsu, Macromol. Chem. Phys. 206, 2171 (2005).

24. H. Yang, K. Nagai, T. Abe, H. Homma, T. Norimatsu, and R. Ramaraj, ACS Appl. Mater. Interfaces 1, 1860 (2009).

25. S. Mulik and C. Sotiriou-Leventis, Aerogels Handbook, Advances in Sol-Gel Derived Materials and Technologies, M. Aegerter, N. Leventis, and M. Koebel (eds.) (Springer, New York, 2011).

26. S. A. Al-Muhtaseb and J. A. Ritter, Adv. Mater. 15, 101 (2003).

27. R. Giles, I. Kim, W. E. Chao, J. Moore, and K. W. Jung, J. Chem. Edu. 91, 1220 (2014).

28. J. Matsuo, Chemistry and Education 61, 244 (2013).

29. T. Yamagishi, M. Nomoto, S. Yamashita, T. Yamazaki, Y. Nakamoto, and S. Ishida, Macromol. Chem. Phys. 199, 423 (1998). 